\title{
FULL CONTOURED TOOTH-IMPLANT SUPPORTED 3-POINTIC ALL-CERAMIC DENTURE DURING OCCLUSAL LOAD TRANSFER IN LATERAL REGION
}

Implant and a tooth supported dentures are avoided by dentists because of uneven distribution of occlusal loads between a stiffer implant and a more pliable tooth. The hypothesis was that a 3-point all-ceramic bridge supported on a natural second premolar tooth and a two-pieces typical implant bears safely mastication loads. The finite element analysis showed that the implant splinted by all-ceramic zirconium bridge with the second premolar was safe under lateral mastication load, but there was found an overload at wide zone of bone tissue around the implant under the load of $800 \mathrm{~N}$. The patients can safely masticate, but comminution of hard food should be avoided and they should be instructed that after such an indiscretion they need to contact a dental professional, because, in spite of integrity of the prosthesis, the bone tissue around the implant may fail and there is a hazard of intrusion of the tooth.

Keywords: biomaterials, denture, zirconium oxide, titanium implant, bone tissue

\section{Introduction}

Prosthesis fixed on a tooth and an implant in lateral zones of a jaw is a questionable solution for many dentists. Special caution is advised when treatment based on a tooth-implant splint is planed [1-3]. In the result of the dissimilar mobility between the implant and the tooth the higher bending moment is induced in stiffer implantologic support which may fail or lose osseointegration [4-11].

The results of previous research show that the distribution of loads depends on translational and rotational mobility of prosthesis on the supports $[12,13]$. The mobility is related to a rigid or non-rigid connection [1]. Non-rigid connection has a little worse clinical success [4]. However, rigid connection also has flexibility to some extent. Each implant system is specific in regards to rigidity [14], as it has stiffness related to the implant abutment and the screw. Finite element analysis whose efficiency in denture biomechanics is widely presented provide detailed data of the load transfer [15]. In twodimensional study [4] the horizontal stiffness of an implant and a bridge is not taken into consideration. Meanwhile, oblique bending from the lateral loads and torsion have detrimental effects $[16,17]$. Clinicians need to have engineering data in regard to commercial implant systems and their performance under a denture connected to a natural tooth.

The aim of the study was analysis of the transfer of mastication load in a 3-point full-ceramic bridge in the lateral zone supported on a natural tooth and an implant. The hypothesis of the research was that a 3-point full-ceramic bridge supported on the natural second premolar and a twopieces implant with a diameter of $4.0 \mathrm{~mm}$ and an abutment screw of $1.5 \mathrm{~mm}$ bears safely mastication loads.

\section{Methods}

Standard engineering computer-aided design and finite element analysis software CAD/FEA (Solidworks; Dassault Systèmes SolidWorks Corp.) was used in simulation tests of the transfer of mastication loads.

TABLE 1

Two-piece implant dimensions

\begin{tabular}{|c|c|c|c|}
\hline \hline \multirow{2}{*}{ Dimensions } & \multicolumn{3}{|c|}{ Part } \\
\cline { 2 - 4 } & Implant & Abutment & Screw \\
\cline { 2 - 4 } & {$[\mathrm{mm}]$} & {$[\mathrm{mm}]$} & {$[\mathrm{mm}]$} \\
\hline Diameter & 4,00 & 5,50 & 1,50 \\
\hline Length & 12,00 & 11,4 & 6,25 \\
\hline
\end{tabular}

A model of a two-piece dental implant of the size shown in TABLE 1 was created to carry out the research (Bredent Sky Implant, with simplified implant/abutment socket to the hexagonal geometry). A simplified model of a mandibular segment composed of trabecular and cortical bone. Sufficient thickness 1.5-2.0 mm of cortical bone and relatively dense trabecular bone were assumed to simulate an equivalent of "BD2" bone type acc. to Lekholm and Zarb [18]. An atrophied alveolar ridge [4], characteristic of most of the cases when a patient undertakes implantoprosthetic treatment after a long time from extraction, was selected for the research.

* SILESIAN UNIVERSITY OF TECHNOLOGY, INSTITUTE OF ENGINEERING MATERIALS AND BIOMATERIALS, FACULTY OF MECHANICAL ENGINEERING, 18 A KONARSKIEGO STR., GLIWICE 44-100, POLAND

\# Corresponding author: jaroslaw.zmudzki@polsl.pl 

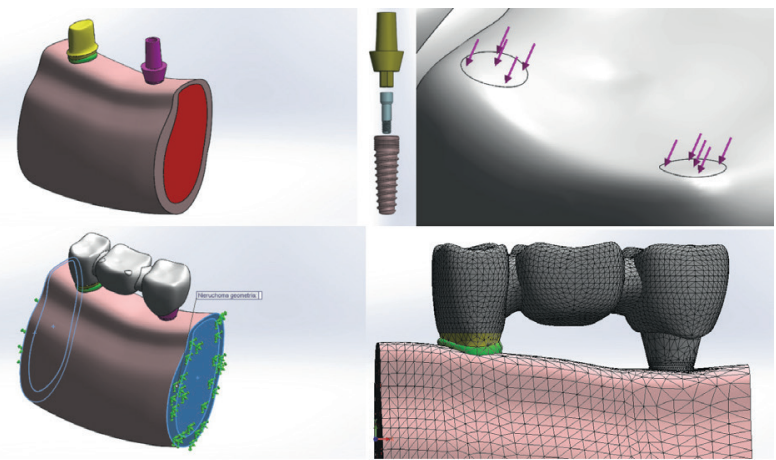

Fig. 1. The model of manbibular bone with a two-piece implant of $4.0 \mathrm{~mm}$ in diameter and $12 \mathrm{~mm}$ in lenght co-working with a 3-pointic bridge connected with the second premolar tooth

A higher implant abutment is usually required in such a situation because of a thicker mucous membrane. The model of the bridge was simplified in relation to anatomical features assuming the average sizes used in the designing process. Total adherence between all the components was assumed (Fig.1). It allows to generate a compatible mesh between the solids on the node-to-node basis. At this stage the non-linear analysis of adherence which can be estimated in relation to the basic linear analysis was abandoned. All materials were modeled as linear isotropic elastic with their properties showed in TABLE 2 . The thickness of periodontal ligament (PDL) was between 0.3$0.5 \mathrm{~mm}$ and its inelastic behavior was imitated with Poisson ratio of 0.45 .

TABLE 2

Material properties

\begin{tabular}{|c|c|c|}
\hline \hline Material & $\begin{array}{c}\text { Young modulus (E) } \\
{[\mathrm{MPa}]}\end{array}$ & Poisson ratio $(v)$ \\
\hline Cortical bone & 13700 & 0,30 \\
\hline Cancellous bone & 1370 & 0,30 \\
\hline Pure Ti & 102700 & 0,31 \\
\hline Ti alloy (Ti6Al4V) & 114000 & 0,31 \\
\hline Dentine & 18600 & 0,31 \\
\hline Zirconium dioxide & 200000 & 0,31 \\
\hline PDL & 170 & 0,45 \\
\hline
\end{tabular}

The action of occlusal forces on two buccal cusps of the pontic was simulated by application of a force of $200 \mathrm{~N}$ characteristic of natural mastication of foods. The angulation of the forces equal to $45^{\circ}$ was assumed (Fig.1) [17]. An action of the mastication force of $800 \mathrm{~N}$ (a result from a high range of forces for natural dentition during mastication of hard foods or frequently occurring cases of pathological occlusion, especially night bruxism) was also analysed. All the degrees of freedom were blocked on sections of the mandibular model which is shown on Fig.1.

\section{Results}

The results of the analysis were evaluated in Huber-Mises criterion of maximal distortion strain energy and maximal

principal stress. The stresses in the bridge under maximal occlusal force of $800 \mathrm{~N}$ were shown on Fig.2 and Fig. 3.

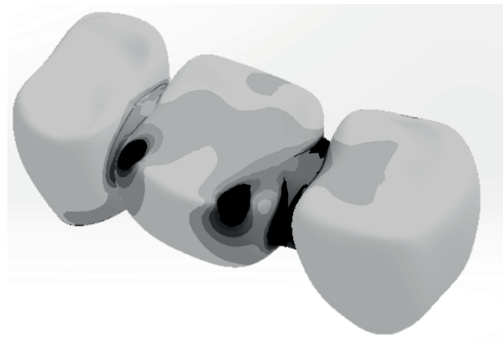

a)

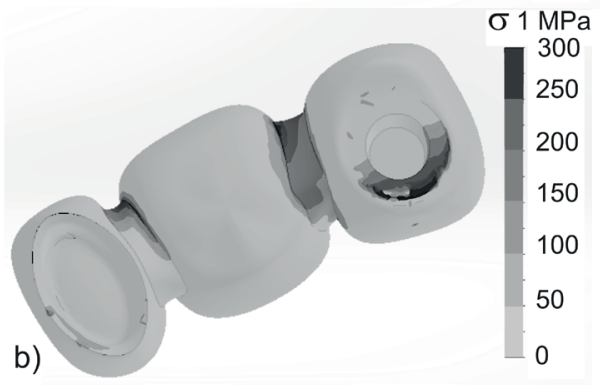

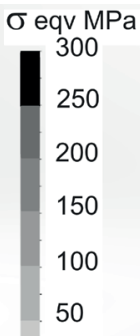

Pa
50
50
50
00

Fig. 2. Equivalent Huber-Mises' stress and first principal (tensile) stress in the full-ceramic bridge under occlusal load of $800 \mathrm{~N}$
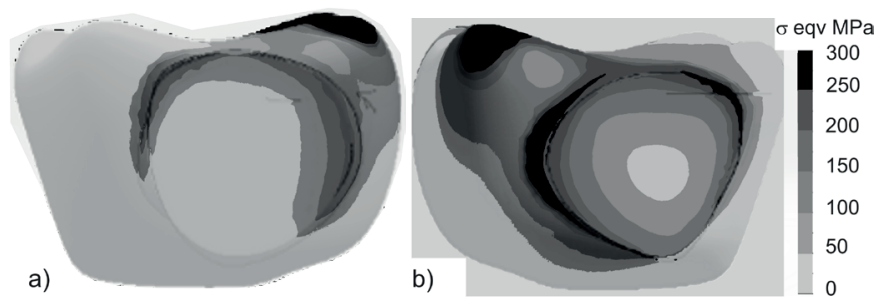

Fig. 3. Equivalent Huber- Mises' stress in the full-ceramic bridge under occlusal load of $800 \mathrm{~N}$ in the cross-section by connector proximal to tooth (a) and to implant (b)

The highest stress in the ceramic bridge at the connector nearer to the implant was below zirconium tensile strength. The stresses in the implant assembly under maximal occlusal force of $800 \mathrm{~N}$ were shown on Fig.4 and Fig.5.

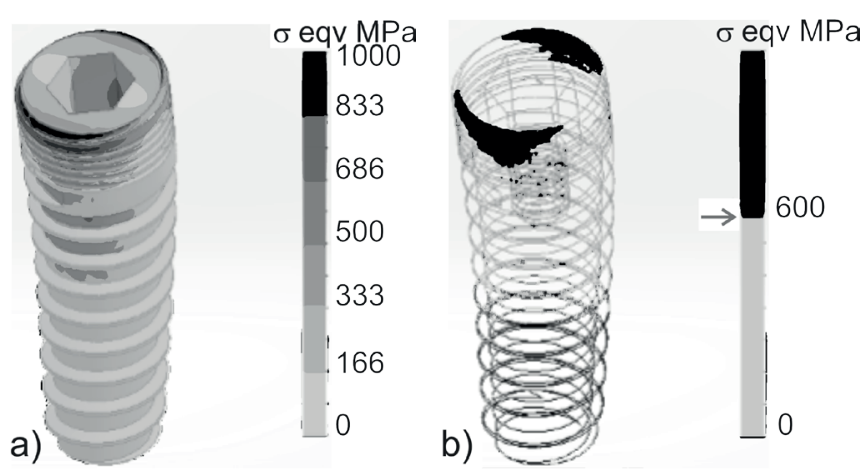

Fig. 4. Equivalent Huber-Mises' stress in the implant under occlusal load of $800 \mathrm{~N}$ : (a) isometric sketch of the implant, (b) the area of the implant in which the stresses exceed $600 \mathrm{MPa}$ 

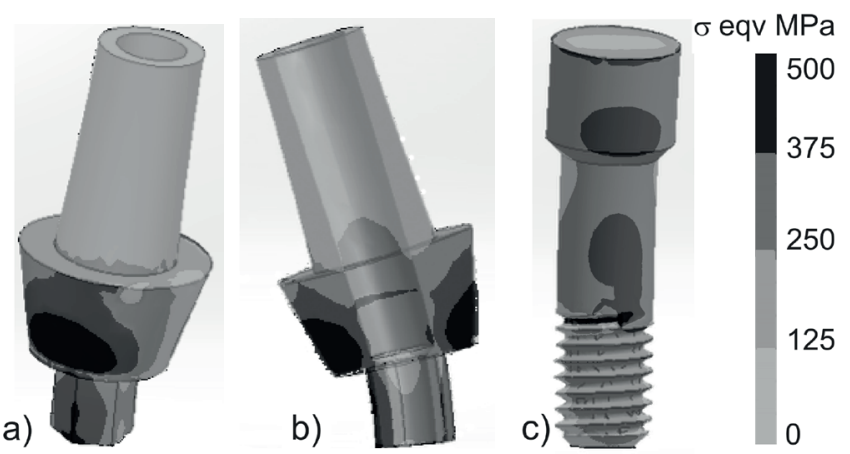

Fig. 5. Equivalent Huber-Mises' stress under occlusal load of $800 \mathrm{~N}$ in the abutment (a) isometric view and (b) cross-section and in the abutment screw (c)

The stresses in bone tissue surrounded the implant under occlusal force of $800 \mathrm{~N}$ and during bearing the mastication load was compared on Fig.6. The areas of the bone tissue in which the stresses exceed allowable instantaneous limit of 140 $\mathrm{MPa}$ and average allowable fatigue limit of $30 \mathrm{MPa}$ [19] were visualized.
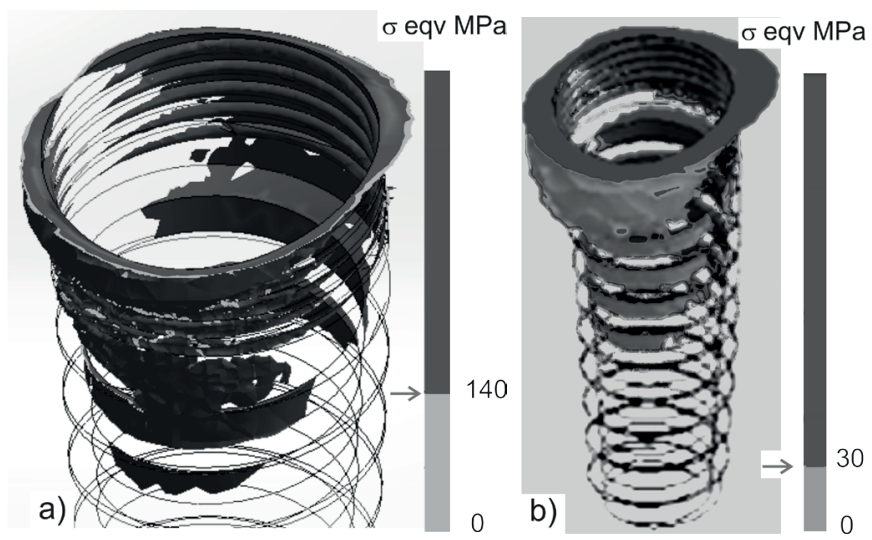

Fig.6. The zones of overloading in bone tissue around the implant under occlusal load of $800 \mathrm{~N}$ (a) and during bearing mastication load of $200 \mathrm{~N}(\mathrm{~b})$

The stresses in the tooth associated with bearing the mastication load were shown on Fig.7.a. Tooth displacement under mastication load shown on Fig.7.b was in agreement with realistic limit.

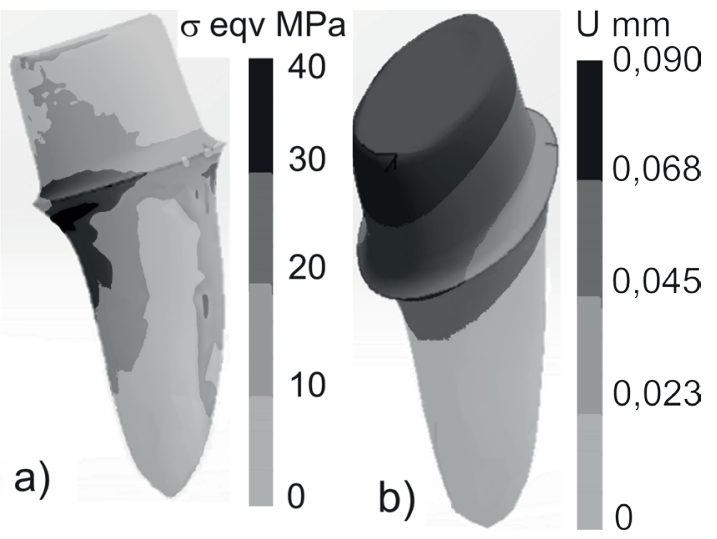

Fig.7. Equivalent Huber-Mises' stress in supporting tooth under mastication load of $200 \mathrm{~N}$ (a) and tooth displacements (b)

\section{Discussion}

The model was simplified which can influences the values of the analysed stress. The analysis was done in the linear elastic range with total adherence between the parts. A non-linear solution with contacts better mimics realistic behavior, however, the results strongly depend on mesh quality on contacting interfaces, as also frictional condition which is not congruent in studies [20,21]. In specific range an increase of the stress in bone tissue around the implants is influenced by anisotropic values of the bone [22], however, in most works

because of the problems with orienting of the coordinating system around the alveolar processes are used linear isotropic models for bone tissues behavior [13,23]. Oblique direction of occlusal loads has a significant impact on stresses when comparing to directional bone tissue elasticity. The assumption of vertical occlusal forces is the reason of underestimation of the stresses [15-17]. The values of the forces sufficient for fragmentation of foods are within the range of $65-165 \mathrm{~N}$ [15]. In the presented analysis that higher values of mastication load and maximal occlusal force and their oblique acting were assumed to simulate the most unfavorable scenario.

In the work [13] a similar tooth-implant bridge fixed on implant of $4.5 \mathrm{~mm}$ in diameter and $13 \mathrm{~mm}$ in length (Frialit-2 root-form implant) was analyzed. Alveolar bone in similar condition categorized as "Type 2 " is also overloaded around the implant neck (in spite of the relatively high value of $170 \mathrm{MPa}$ of Young modulus of periodontal ligament). The most unfavorable case of loading [13] is oblique multiple forces: $100 \mathrm{~N}$ on premolar (implant), $200 \mathrm{~N}$ on pontic and $200 \mathrm{~N}$ on the molar tooth. In this case of load the maximal value of equivalent Huber-Mises stress in bone is beyond $70 \mathrm{MPa}$ [13] and equivalent Huber-Mises strain reaches almost $4000 \mu \mathrm{m} / \mathrm{m}$ which is regarded as critical for destruction of bone tissue [23].

However, FEA results are sensitive to mesh quality with tendency to overestimation of maximal value of stresses around the dental implant neck because of the presence of the singular point at the margin of bone contacted with the implant [24]. The better manner of estimation of an implant solution is to show the zone of destruction or the zone exposed to atrophy from overloading. Especially, that in case of cyclic mastication loads, the stresses beyond 28-35 MPa are critical for bone tissue disuse at a long-term effect [19]. In presented analysis the zone of atrophy was in agreement with typical bone atrophy at the margin after one year of loading. It is worth mentioning, that the area corresponds to the load of $250 \mathrm{~N}$ which is a high value during mastication. Situation of 1-2 mm marginal bone loss around the implant neck is considered as successful treatment [26], although the implant was $0.5 \mathrm{~mm}$ smaller in diameter and $1 \mathrm{~mm}$ in length, and the cortical bone was less stiff by around $20 \%$ as compared to the implant analyzed in the work [13].

Stresses in the prosthesis and the implant components were lower than the critical values even when the occlusal load of $800 \mathrm{~N}$ was acting. In the work [13] a gold bridge bears safely these mastication loads, nevertheless, all-metallic bridge has higher strength when compared to all-ceramic in regard of tensile. In presented analysis in the all-ceramic bridge the maximal principal stress concentrated mainly on the connector at the implant side and its values were lower than the critical 
tensile strength for yttrium stabilized zirconium ceramics. Equivalent Huber-Mises stresses in the abutment and the screw were below permissible limit for titanium alloys. In the screw the value of stress was lower than yield stress, even when the stress resulting from preload of the screw of app. 200-250 MPa was added [27]. At the margin of the pure titanium implant the compression from abutment caused a plastic deformation, but in the region very located close to the edge. In the distance of some microns from the edge there was the stress below yielding, hence, load transfer at the implant interface will be equally distributed after a plastic deformation at the margin. Local deformation in this region is negligible for the analyzed implant. However, only one implant type was tested in the research. The stress distribution in other implants under the high occlusion load of $800 \mathrm{~N}$ should be investigated [27].

\section{Conclusions}

The analyzed type of the implant placed in standard bone conditions can safely bear loads associated with standard food mastication when it is connected with a 3-pointic bridge supported on the premolar. However, comminution of hard foods and strong biting should be avoided since the level of stress in the bone can be destructive. Patients should be instructed that after such indiscretion they need to contact dental professionals, because, in spite of integrity of the prosthesis, the bone tissue around the implant may fail and there is a hazard of implant loosening and as a final point, a menace of losing the implant together with the supporting tooth.

\section{Acknowledgements}

This publication was financed by the Ministry of Science and Higher Education of Poland as the statutory financial grant of the Faculty of Mechanical Engineering SUT.

Special thanks to student Kamil Musiał who developed finite element model

\section{REFERENCES}

[1] K.X. Michalakis, P. Calvani, H. Hirayama, J Dent Biomech. 3, (2012): DOI: $10.1177 / 1758736012462025$

[2] I.E. Naert, J.A.J. Duyck, M.M.F. Hosny, et al., Clin Oral Implants Res. 12, 237-244 (2001).

[3] T. Lindh, S. Dahlgren, K. Gunnarsson, et al., Int J Prosthodont. 14, 321-328 (2001).

[4] R. Skalak, J Oral Implantol. 12, 350-356 (1986).
[5] L.A. Weinberg, B. Kruger, Oral Surg Oral Med Oral Pathol. 78, 22-27 (1994).

[6] D. Lundgren, L. Laurell, Periodontol 2000. 4, 23-40 (1994).

[7] T. Burak Ozcelik, E. Ersoy, B. Yilmaz, J Prosthodont. 20,1, 1628 (2011). DOI: 10.1111/j.1532-849X.2010.00654.x.

[8] G. Menicucci, A. Mossolov, M. Mozzati, et al., Clin Oral Implants Res. 13, 334-344 (2002).

[9] C.L. Lin, S.H. Chang, J.C. Wang, et al., J Dent. 34, 682-691 (2006).

[10] C.L. Lin, , J.C. Wang, S.H. Chan, Clin Oral Implants Res. 19, 107-117 (2008).

[11] T. Ozcelik, A.E. Ersoy. J Prosthodont. 16, 107-116 (2007).

[12] R. Kayacan, R. Ballarini, R.L. Mullen, J Prosthet Dent. 78, 391-399 (1997).

[13] C.L. Lin, S.H. Chang, J.C. Wang, Chang Gung Med J. 29, $143-$ 153 (2006).

[14] J. Żmudzki, G. Chladek, J. Kasperski, J Mech Med Biol. 12, 1250087(2012).

[15] J. Żmudzki, G. Chladek, J. Kasperski, Biomech Model Mechanobiol. 14, 679-691 (2015). DOI: 10.1007/s10237-0140642-0

[16] Ł. Reimann, J. Żmudzki, L.A. Dobrzański, Acta Bioeng Biomech. 17, 1, 51-59 (2015).

[17] R. Kenney, M.W. Richards, J Prosthet Dent. 80, 5, 55-64 (1998).

[18] U. Lekholm, G.A. Zarb, Patient selection and preparation. In: Branemark PI, Zarb GA, Albrektsson T (eds). Tissueintegrated Prostheses: Osseointegration in Clinical Dentistry. Quintessence, Chicago 1985.

[19] C.L. Lin, J.C. Wang, Y.C. Kuo, J Biomech. 39, 453-463 (2006).

[20] B.R. Merz, S. Hunenbart, U.C. Belser, Int J Oral Maxillofacial Implants. 15, 519-526 (2000).

[21] A.M. O' Mahony, J.L. Williams, P. Spencer, Clin Oral Implants Res. 12,6, 648-657 (2001).

[22] S.M. Alencar, L.B. Nogueira, W. Lealde Moura, et al., J Prosthodont. 20, (2015). DOI: 10.1111/jopr.12384. [Epub ahead of print]

[23] H.M. Frost, Angle Orthod. 64, 175-188 (1994).

[24] J. Żmudzki, W. Walke, W. Chladek, Influence of model discretization density in FEM numerical analysis on the determined stress level in bone surrounding dental implants, in: E. Piętka, J. Kawa Information technologies in biomedicine. Berlin Springer (2008), Advances in Soft Computing 47, 559.

[25] H. Van Oosterwyck, J. Van der Sloten, R. Puers, I. Naert, Mecanica 37, 441-451 (2002).

[26] I.E. Naert, M. Hooghe, M. Quirynen, D. van Steenberghe, Clin Oral Invest. 1, 119-124 (1997).

[27] D. Jörn, P. Kohorst, S. Besdo, et al., J Prosthet Dent. 12, 2, 340-348 (2014). DOI: 10.1016/j.prosdent.2013.10.016. Epub 2014 Feb 14 